\title{
Inovação social ou compensação? Reflexões acerca das práticas corporativas
}

\author{
Luiz Felipe Barboza Lacerda \\ Universidade do Estado do Amazonas (UEA) - Tabatinga / Brasil. \\ Email: luizpsico@hotmail.com
}

\begin{abstract}
Adriane Vieira Ferrarini
Universidade do Vale do Rio dos Sinos (UNISINOS) - São Leopoldo/ Brasil.

Email: adrianevf@unisinos.br
\end{abstract}

\begin{abstract}
Resumo: As fraturas da sociedade salarial e o aumento da precariedade de vida levam diferentes setores a se engajarem em ações sociais. $\mathrm{O}$ artigo analisa $\mathrm{o}$ papel das corporações no enfrentamento dos problemas sociais a partir de um debate sobre o tipo de racionalidade subjacente ao modelo de desenvolvimento globalizado (pautado na razão indolente de Boaventura de Sousa Santos) e da análise da imbricação da economia na estrutura social (através da sociologia econômica). Os resultados demonstram que, apesar de alguns avanços historicamente consolidados, práticas consideradas inovadoras por parte das corporações encontram substantivos desafios para ultrapassarem o nível da compensação, o que se relaciona com a permanência dos princípios da racionalidade mercantil. O estudo conclui que a genuína inovação social necessita considerar uma perspectiva de desenvolvimento e inovação baseada nas liberdades substantivas dos seres humanos.
\end{abstract}

Palavras-chave: inovação social; sociologia econômica; desenvolvimento.

\section{Social innovation or compensation? Considerations on corporate practices}

\begin{abstract}
Fractures in the wage-base society and the increased precariousness of the living conditions across the globe have made different sectors to get involved in social action. The article examines the role of corporations in facing social problems on the basis of a debate about the rationality underlying the model of globalized development (guided by the lazy reason of Boaventura de Sousa Santos) and of the analysis of the overlapping of economy in the social structure (through economic sociology). The results demonstrate that practices that are considered innovative by corporations hardly go beyond the level of compensation, which is due to the permanence of the principles of market rationality. The genuine social innovation must consider a perspective of development based on the substantive freedoms of human beings and be able to establish the effective participation of subjects in the production process of innovation and in the appropriation of its results.
\end{abstract}

Key words: social innovation, economic sociology; development. 


\section{¿Innovación social o compensación? Reflexiones sobre las prácticas corporativas}

Resumen: Las fracturas de la sociedad salarial y la precarización de la vida llevan a diferentes sectores a involucrarse en la acción social. El artículo analiza el papel de las empresas para hacer frente a los problemas sociales a partir de un debate sobre el tipo de racionalidad que subyace el modelo de desarrollo globalizado (guiado por la razón perezosa Boaventura de Sousa Santos) y del análisis de la superposición de la economía en la estructura social (a través de la sociología económica). Los resultados demuestran que, a pesar de algunos avances históricamente consolidados, prácticas consideradas innovadoras por las corporaciones se encuentran con desafíos sustantivos para superar el nivel de compensación, lo cual está relacionado con la permanencia de los principios de la racionalidad mercantil. El estudio concluye que la verdadera innovación social debe tener en cuenta una perspectiva del desarrollo y la innovación basada en las libertades fundamentales de los seres humanos.

Palabras clave: innovación social, sociología económica, desarrollo.

$$
* * *
$$

\section{Introdução}

As análises sobre a atual conjuntura social e econômica não são muito positivas. Desenha-se a fratura do modelo de sociedade desenvolvido sobre a premissa salarial - principalmente no contexto europeu e norteamericano - o qual pulveriza precariedades por todo o globo através do processo de mundialização do mercado e da minimização da figura do Estado como aparelho regulador.

A máxima da era capitalista industrial, que previa relação harmônica entre crescimento econômico e desenvolvimento social, mostra-se frágil. $\mathrm{O}$ capitalismo acabou promovendo processos degradantes de exploração e exclusão de grande contingencial humano, que se encontra privado da satisfação de necessidades básicas e de direitos fundamentais.

Como atores envolvidos neste quadro de degradação da sociedade salarial - que Castel (1997) denomina “a questão social” - e de produção de territórios de exclusão - denominados por Santos (2002) de territórios de não existência ou de ausência - empresas e corporações são chamadas a assumirem suas responsabilidades e a desenvolverem ações no sentido de minimizar as mazelas provocadas por décadas de primazia da racionalidade guiada pela maximização dos lucros.

Neste sentido, ressurge uma área específica do conhecimento denominada Sociologia Econômica que, através de uma série de reflexões a respeito da importância do papel do empreendedor e da inovação tecnológica, busca aproximar as empresas das problemáticas sociais. Deste interesse emergem os conceitos de responsabilidade social e, mais recentemente, de inovação social. A responsabilidade social, através de seus princípios, 
metodologias e indicadores, contribuiu nas últimas três décadas para a realização de ações voltadas à melhoria de condições sociais internas e externas às empresas, mas também serviu em muitos casos como mera estratégia de marketing empresarial. A inovação social ganhou força no Brasil na última década e já representa um novo fôlego na proposição de conjugar maximização de lucro com criação de valor social, mas a produção teórica no campo alerta para o risco de um novo modismo ou tido como saída milagrosa para a regulação de mazelas da questão social na contemporaneidade.

Mas, de fato, será possível combinar objetivos econômicos e sociais sob o viés de uma racionalidade mercantil que por definição e evidência histórica prioriza o mercado em detrimento das condições humanas? Ou, como defendem alguns críticos do sistema (Soares, 2004; \& Mészáros, 2003, 2002), inovação social no âmbito corporativo e responsabilidade social não passam de estratégias instrumentais que buscam, através da apropriação do discurso do social e da implementação de ações residuais, reinventar as manifestações da racionalidade estritamente guiada pelo lucro?

No cerne das respostas a estas perguntas encontra-se a fundamental discussão a respeito do tipo de desenvolvimento almejado e das melhores formas de intervir para sua consecução. Para tanto, nesse artigo será analisado o papel das corporações no enfrentamento dos problemas sociais a partir, inicialmente, de um debate em torno do tipo de racionalidade subjacente ao modelo de desenvolvimento globalizado e da explicitação dos pressupostos teóricos da Sociologia Econômica em sua tentativa de compreender o econômico no contexto histórico das relações sociais. Posteriormente será feita uma reflexão acerca das possibilidades e desafios para a instauração de práticas de inovação social por parte das corporações a partir de uma perspectiva de desenvolvimento baseada nas liberdades substantivas dos seres humanos.

\section{Capitalismo, modernidade e a crítica da razão indolente}

A sociedade moderna desenvolveu-se sob a premissa do cientificismo e da racionalidade lógica. No início desta era, inclusive, acreditava-se ser possível analisar e compreender a realidade social sob os mesmos supostos utilizados nas ciências naturais, o que engendrou o positivismo (com seus princípios reducionistas e deterministas) como perspectiva de análise.

Boaventura de Sousa Santos, sociólogo português com vasta e influente obra a respeito dos processos sociais contemporâneos, propõe a necessidade de uma crítica à razão que chama de indolente e que é a própria razão moderna. A razão moderna ou indolente produziu uma crítica segregativa sobre a realidade social porque teve como referência o padrão ocidental, científico, industrial, patriarcal e racial. Santos (2002) distingue quatro dimensões da Razão Indolente: 
$1^{\text {a }}$ A Razão Impotente, caracterizada pela perplexidade frente às concepções fatalistas. Ela origina-se na consolidação do Estado Liberal na Europa e na América do Norte e possui, como contextos sociopolíticos para o seu desenvolvimento, as revoluções industriais, o capitalismo, o colonialismo e o imperialismo;

$2^{a}$ A Razão Arrogante, que não produz certa crítica necessária, pois se sente livre para traçar seus próprios parâmetros de prioridades aquém de qualquer vínculo com o outro. Sob o desenvolvimento da razão arrogante se constitui o ambiente para a razão culturalmente unilateral, exploratória e discriminativa do racismo e da escravidão, dentre outras manifestações;

$3^{\text {a }}$ A Razão Metonímica, que é definida como a ideia de totalidade, sob a forma de ordem; é a parte tomada pelo todo. Ela reivindica-se como a única forma de verdade. No sentido de sobrepor-se ao diferente e desconhecido, a metonímica surge como uma ideia de racionalidade indolente que crê possuir sua própria totalidade hermética, que depende apenas de si mesma para um pleno e satisfatório funcionamento;

$4^{\mathrm{a}}$ A Razão Proléptica, que julga saber tudo a respeito do futuro e o concebe como uma progressão linear, automática e infinita do presente. Assim, serve como proteção às demais facetas da razão indolente, rejeitando historicamente as teorias do caos e da complexidade e mantendo uma ordem natural frente aos processos sociais e um desejável domínio e seguridade sobre o futuro.

Sob a égide da Racionalidade Indolente, inúmeras experiências sofrem um processo de inexistência social e são postas à margem da realidade. Há produção de não existência sempre que uma dada entidade é desqualificada e tornada invisível, intangível, precária ou descartável. Santos (2007) identifica cinco lógicas ou modos de produção da não existência:

1) Monocultura do saber: consiste na transformação da ciência moderna e da alta cultura como únicas formas de verdade e de qualidade estética. Inexistência é ignorância ou incultura;

2) Monocultura do tempo linear: origina a ideia de que a história tem sentido e direção únicos e conhecidos - geralmente chamados de desenvolvimento, progresso, modernização, crescimento e globalização. O tempo é tido como linear; à frente deste tempo estão os países centrais do sistema mundial com suas tecnologias, instituições e culturas. Inexistência é aquilo que é pré-moderno, obsoleto ou subdesenvolvido;

3) Monocultura da naturalização das diferenças: assenta sobre a lógica das classificações das populações, naturalizando hierarquias. Inexistência, neste caso, é a inferioridade insuperável dada por características naturais. O inferior não pode apresentar-se como alternativa credível a quem é superior; 
4) Lógica da escala dominante: todas as realidades que se apresentam sob as diferentes escalas locais parecem irrelevantes. As lógicas adotadas pela racionalidade hegemônica são a global e a universal. A inexistência é construída sobre o rótulo do local, tornando a realidade particular como alternativa incredível para o que existe na esfera global ou universal. Inexistente aqui é ser pequeno, colonial ou comunitário;

5) Monocultura dos critérios produtivos capitalistas: baseia-se na ideia de que o desenvolvimento econômico é racional e inquestionável. Neste caso, a inexistência está posta sob o rótulo de improdutivo que se manifesta como infertilidade (no caso da natureza) e como preguiça, desemprego e incapacidade profissional (no caso do trabalho humano).

As cinco formas de produção de não existência propagadas pela Razão Indolente (o ignorante, o residual, o inferior, o local e o improdutivo) recaem sobre a esfera social e constituem critérios, que são a alavanca da discriminação. Tais critérios produzem o desperdício das inúmeras experiências que compõem o contemporâneo em nome de uma única e estrita forma de perceber e viver a realidade, a qual se vincula fundamentalmente às lógicas de mercado e à busca da maximização dos ganhos.

A Razão Indolente, portanto, refere-se à determinada racionalidade cuja centralidade encontra-se no homo economicus (Reis, 1989) como agente que guia suas ações invariavelmente para a maximização dos ganhos, justificando os meios para alcançar os fins desejados. A lógica historicamente empregada pelas corporações e seus agentes possui relação direta e causal com os processos de exclusão social e a criação dos territórios de não existência localizados do outro lado da linha abissal.

A história da sociedade capitalista contemporânea é a própria história da globalização de um localismo europeu, ou seja, em um modelo de desenvolvimento baseado no expansionismo produtivista e tecnológico, que trouxe inegáveis benefícios à humanidade, mas também acirrou desigualdades. Trata-se de um modelo econômico que trouxe desenvolvimento para pequenas regiões do planeta, especialmente do Norte, mas não viabilizou desenvolvimento (entendido como satisfação das necessidades humanas) para a maioria. Ao contrário, os recursos naturais têm sido consumidos de forma insustentável e a desigualdade ampliada. (Ferrarini, 2008: 26).

O cenário global de pobreza e desigualdade social evidencia a problemática da indolência da razão na contemporaneidade. Diariamente, cerca de 50 mil pessoas morrem por dia vitimas devido à fome e doenças evitáveis. Nos últimos 30 anos, a renda dos países com 20\% da população mais rica cresceu cerca de três vezes mais que a dos países com população $20 \%$ mais pobre. Quanto à erradicação do trabalho infantil e superação da miséria, apesar da queda substancial nos países em desenvolvimento, as metas estipuladas pela Organização das Nações Unidas (ONU) encontramse longe de serem atingidas (Ferrarini, 2008). 
A razão moderna produziu análises a partir de certos parâmetros, mas pecou no processo de autocrítica a respeito de seus próprias referências e delimitações. Daí a necessidade de uma crítica da Razão Indolente, a qual produz um alerta contra o desperdício das inúmeras realidades e possibilidades ignoradas pela racionalidade moderna porque (Santos, 2002):

1) A experiência social em todo o mundo é muito mais ampla e variada do que a tradição científica e filosófica ocidental conhece ou considera importante;

2) Esta experiência social está sendo desperdiçada e é deste desperdício que se nutrem as ideias fatalistas de que não há mais saídas, de que as coisas são e serão sempre assim ou que as dinâmicas sociais vigentes hoje são eternas e impermutáveis;

3) Por fim, para tornar visíveis e reconhecidas as experiências sociais subjugadas pela lógica hegemônica, pouco serve o uso das ciências sociais convencionais; são necessários passos adiante no sentido de criar novas ferramentas de análise, produzindo assim, outra racionalidade.

Frente ao quadro de limitações conceituais e de graves problemas sociais, a Sociologia Econômica é requisitada a pensar a relação entre o social e econômico e contribuir para a compreensão do papel das corporações frente à pressão de tornarem-se agentes de transformação da realidade social.

\section{A sociologia econômica em foco}

Swedberg (2004: 2), articulando pensadores como Marx, Weber, Schumpeter e Polanyi, afirma que:

a sociologia econômica pode ser definida de modo conciso como a aplicação de ideias, conceitos e métodos sociológicos aos fenômenos econômicos - mercados, empresas, lojas, sindicatos, e assim por diante. Apoiando-se no enfoque de Max Weber, a sociologia econômica estuda, tanto o setor econômico na sociedade ("fenômenos econômicos”), como a maneira pela qual esses fenômenos influenciam o resto da sociedade ("fenômenos economicamente condicionados") e o modo pelo qual o restante da sociedade os influencia ("fenômenos economicamente relevantes").

As análises realizadas por Swedberg traçam um panorama histórico e conceitual da Sociologia Econômica nos Estados Unidos e na Europa, desde a década de 1980 até a atualidade. Ao longo desse percurso, evidenciaram-se dificuldades na construção de marcos teóricos que questionassem o dogma da autonomia da esfera econômica e promovessem a devida aproximação entre as expressões da questão social e a economia formal. 
Mark Granovetter, incorporando a discussão das redes, tornou essa aproximação mais evidente. De acordo com Raud-Mattedi (2005), Granovetter concordava com os preceitos de Max Weber ao afirmar que o mercado está imbricado na esfera social, mas não é fruto de processos naturais e harmônicos. As instituições, guiadas pela regularidade e normatividade da ordem moral e técnica, apresentam dificuldades em absorverem a racionalidade diferenciada do contexto social e incorpora-la no planejamento de suas estratpégias de intervenção.

Neste sentido, na visão granovetteriana, as redes seriam o espaço de criação, articulação e regulação da aproximação entre empresas e o campo social, pois, guiadas por determinada dinâmica de imbricação e desimbricação, elas possuem a flexibilidade de, ora atender a demanda de uma das partes, ora de outra, trazendo à tona pertinentes discussões sobre confiança, comunicação e objetivos comuns, dentre outros temas. A contribuição das redes na busca de aproximar economistas da dimensão social se traduziria, portanto, naquilo que Swedberg (2004) - embasado nos escritos de Polanyi (2008) - chamou de enraizamento, conceito que busca a centralidade do local no planejamento e gestão dos processos de intervenção.

Acolhendo essa sugestão, a tarefa da sociologia econômica seria descrever o modo pelo qual as ações econômicas são estruturadas por meio de redes. Em suma, as ações econômicas não acompanham os caminhos concisos e diretos da maximização, tal como reivindicam os economistas; acompanham muito mais os caminhos consideravelmente mais complexos das redes existentes. Os economistas estavam errados, mas não tanto por conta de razões psicológicas correlacionadas ao homo economicus ou de fato pelo quão racionais são ou não as pessoas; os economistas como que falharam em apreender a importância da estrutura social na economia. (Swedberg, 2004: 17).

Em seu estudo sobre a influência das redes nas intervenções econômicas em contextos sociais, Granovetter alerta para a necessidade de se estar atento à ambiguidade dos atores nas redes, de clarear o papel do Estado nessas relações e de compreender os mecanismos de encaixe e desencaixe no enraizamento das dinâmicas coletivas.

Contudo, a análise aprofundada das elaborações granovetterianas evidencia a centralidade da concepção de um sujeito (aquele que protagoniza as redes) guiado por motivações racionais de maximização do lucro a partir da realidade concebida como escassez de recursos, em que a relação custo-benefício volta-se ao ganho individual ou corporativo. Do ponto de vista dos interesses sociais, pouco adianta considerar a estrutura social dentro do contexto econômico se nas redes impera a racionalidade mercantil. Isto justifica a emergente necessidade de inovar, antes de tudo, a própria racionalidade predominante. 
A concepção de ser humano preconizada pela Sociologia Econômica parece não romper com o predomínio de uma racionalidade mercantil (identificada na Razão Indolente), a qual acaba por desconsiderar a diversidade de modos de vida e de produção presentes no campo social (teórico e empírico) através de uma racionalidade Arrogante, Metonímica e Proléptica. Tal racionalidade constituiu alicerces epistemológicos que acabaram por exercer função explicativa e legitimadora do fenômeno da desigualdade social e da pobreza, além de engendrarem uma racionalidade Impotente frente aos desafios atuais.

Em última análise, as intervenções guiadas por estas lógicas, como apontam alguns estudos (Santos, 2002; Guattari, 2003; Meszaros 2020), apresentam a tendência de globalizar mercados locais em busca da implementação de uma escala dominante e, para isto, naturalizam as diferenças de cada contexto dentro de um quadro global de desigualdades implementando, por fim, o direcionamento à monocultura dos processos produtivos.

\section{Inovar é vital, mas como? E para quê?}

O economista Joseph Schumpeter é referência fundamental na Sociologia Econômica para o debate sobre a inovação. Nascido na atual República Checa, em 1883, foi colega de Marshall e Keynes, além de herdar de Marx uma visão dinâmica dos processos econômicos. Em sua Teoria do Ciclo Econômico, Schumpeter aponta a inovação como principal fator de desequilíbrios e reequilíbrios do mercado e consequentemente de avanço da sociedade. Na medida em que, para o autor, as inovações são cíclicas e rotineiras, o mercado adquire característica de crescimento harmoniosamente sistêmico. Na teoria shumpeteriana, a inovação pode ocorrer quando há introdução de um novo bem, um novo método, um novo campo (mercado), uma nova matéria-prima ou a emergência de novos atores.

Bignetti (2011) afirma que a inovação se tornou tema obrigatório nas discussões sobre competitividade e desenvolvimento econômico, aparecendo na mídia em geral como sinônimo de novidade. O uso indiscriminado vulgarizou o termo ao ponto de relacioná-lo exclusivamente aos processos de geração de valor econômico. (Bignetti, 2011: 2).

Evidencia-se assim que os processos de inovação protagonizados pelas corporações geralmente tem como objetivo a produção do fascínio frente a um produto mais atualizado. São as chamadas inovações tecnológicas, que têm como tendência a apropriação de valores e ideias sociais cooptadas para a modelação das marcas e produtos , o protagonismo de agentes econômicos e a centralidade da empresa na produção da inovação, a qual geralmente desenvolve uma política de não cooperação e de proteção dos conhecimentos desenvolvidos. (Bignetti, 2011).

Pelo viés mercadológico de constante produção do desejo ao consu- 
mo, que ao longo do tempo se propaga por todo sistema empresarial, encontramos as variações deste tipo de inovação como inovação administrativa, de consumo e de marketing, entre outras. Na esteira de inovar constantemente, a própria conceituação de inovação se renova e, na contracorrente do avanço tecnológico, emerge a inovação social.

Afirma Bignetti (2011, p. 3) que “a inovação social é [...] o resultado do conhecimento aplicado às necessidades sociais através da participação e da cooperação de todos os atores envolvidos, gerando soluções novas e duradouras para grupos sociais, comunidades ou para a sociedade em geral”. Caracterizando-se como um campo de estudos relativamente novo, há poucas referências teóricas sobre inovação social, o que dá margem a diversas formas de conceituação, como demonstra o quadro a seguir:

\section{Tabela 1: Conceitos de inovação social. Fonte: Bignetti (2011)}

\begin{tabular}{|l|l|}
\hline \multicolumn{1}{|c|}{ Autores } & \multicolumn{1}{c|}{ Conceito } \\
\hline $\begin{array}{l}\text { Taylor } \\
(1970)\end{array}$ & $\begin{array}{l}\text { Formas aperfeiçoadas de ação, novas formas de fazer as coisas, novas } \\
\text { invenções sociais. }\end{array}$ \\
\hline $\begin{array}{l}\text { Dagnino e } \\
\text { Gomes } \\
(2000)\end{array}$ & $\begin{array}{l}\text { Conhecimento - intangível ou incorporado a pessoas ou equipamentos, } \\
\text { tácito ou codificado - que tem por objetivo o aumento da efetividade dos } \\
\text { processos, serviços e produtos relacionados à satisfação das necessidades } \\
\text { sociais. }\end{array}$ \\
\hline $\begin{array}{l}\text { Cloutier } \\
(2003)\end{array}$ & $\begin{array}{l}\text { Uma resposta nova, definida na ação e com efeito duradouro, para uma } \\
\text { situação social considerada insatisfatória, que busca o bem-estar dos } \\
\text { indivíduos e/ou comunidades. }\end{array}$ \\
\hline $\begin{array}{l}\text { Review } \\
(2003)\end{array}$ & $\begin{array}{l}\text { O processo de inventar, garantir apoio e implantar novas soluções para } \\
\text { problemas e necessidades sociais. }\end{array}$ \\
\hline $\begin{array}{l}\text { Rodrigues } \\
(2006)\end{array}$ & $\begin{array}{l}\text { Mudanças na forma como o individuo se reconhece no mundo e nas } \\
\text { expectativas recíprocas entre pessoas, decorrentes de abordagens, práticas } \\
\text { e intervenções. }\end{array}$ \\
\hline $\begin{array}{l}\text { Moulaert et al. } \\
(2007)\end{array}$ & $\begin{array}{l}\text { Ferramenta para uma visão alternativa do desenvolvimento urbano, focada } \\
\text { na satisfação de necessidades humanas (e empowerment) através da } \\
\text { inovação nas relações no seio da vizinhança e da governança comunitária. }\end{array}$ \\
\hline $\begin{array}{l}\text { Mulgan et al. } \\
(2007)\end{array}$ & $\begin{array}{l}\text { Novas ideias que funcionam na satisfaça de objetivos sociais; atividades } \\
\text { inovativas e serviços que são motivados pelo objetivo de satisfazer } \\
\text { necessidades sociais e que são predominantemente desenvolvidas e } \\
\text { difundidas através de organizações cujos propósitos primários são sociais. }\end{array}$ \\
\hline $\begin{array}{l}\text { Murray et al. } \\
(2010)\end{array}$ & $\begin{array}{l}\text { Novas ideias (produtos, serviços e modelos) que simultaneamente } \\
\text { satisfazem necessidades sociais e criam novas relações ou colaborações } \\
\text { sociais. Em outras palavras, são inovações que, ao mesmo tempo, são boas } \\
\text { para a sociedade e aumentam a capacidade de ação da sociedade. }\end{array}$ \\
\hline
\end{tabular}

Diferentemente da inovação tecnológica, a inovação social busca não apropriar-se do valor criado - que é um valor social - tendo a própria comunidade como protagonista e os atores sociais como centrais no processo de inovação. Além disso, a inovação social vale-se de conhecimentos originados no ambiente comunitário e sempre deve imprimir a lógica de compartilhamento das informações e de cooperação das ações. As estratégias 
devem possibilitar a substituição do imperativo da competição por práticas colaborativas de governança. Por fim, conceitualmente, as inovações sociais também se diferem da clássica perspectiva schumpeteriana na medida em que os locais de suas intervenções são as comunidades e não mais as empresas.

Contudo, Bignetti (2011) salienta que, apesar de uma rápida análise apresentar dissonâncias marcantes entre as duas formas de inovação (tecnológica e social), não se deve cair no erro analítico de interpretá-las como excludentes. Não discordamos do autor sobre as peculiaridades da inovação social e seu potencial em abrandar mazelas sociais de determinada localidade, ou ainda, sobre sua possível complementaridade com outras formas de inovação. Devemos, inclusive, levar em consideração o apanhado de experiências historicamente consolidadas como inovadoras que vêm cada vez mais produzindo a ampliação dos conceitos democráticos e participativos da esfera social.

Temos encontrado casos exemplares em experiências protagonizadas pela sociedade civil através de suas organizações e movimentos sociais em parceria com o Estado. Santos (2004) apresenta estudo sobre o Orçamento Participativo de Porto Alegre, o qual se constituiu não apenas concretamente como estrutura comunitária de participação e interlocução popular com atores governamentais, como também inaugurou amplo imaginário de uma sociedade participativa radicalmente democrática com significativa força e relevância.

Da mesma forma, o Banco de Crédito Palmas, no conjunto habitacional Palmeiras em Fortaleza (Ceará), envolve mais de 32 mil moradores, através do crédito popular para a produção e consumo. Há 15 anos a comunidade constrói um comércio local forte que, de acordo com a Secretária Nacional de Economia Solidária (um de seus principais apoiadores), caracteriza-se como amplo projeto de inovação social, promovendo a superação da pobreza naquela região. (www.bancopalmas. org.br).

Salienta-se que experiências exitosas de inovação social possuem como característica central a prévia organização comunitária e o apoio intensivo de órgãos públicos governamentais em sua implementação. Não há dúvidas acerca do potencial da inovação social em superar o quadro de desigualdades sociais; nossa reflexão se refere às possibilidades e limites da inovação social por parte de corporações regidas pela racionalidade mercantil, a qual se caracteriza pelo predomínio de motivações econômicas, pelo conceito de desenvolvimento como expansionismo produtivista ilimitado e por concepções de participação por vezes mais executivas do que decisórias (ou ainda tuteladas, em diferentes níveis e dinâmicas interacionais). Empreendido pelo setor corporativo, o discurso da inovação social como ferramenta de mudança social, na maior parte dos casos ${ }^{1}$, não explicita as limitações procedentes dessa racionalidade e suas implicações na 
forma e no resultado da intervenção social.

Estudos (Santos, 2002; Mészáros, 2002; Soares, 2002; Guattari, 2003; Guattari \& Rolnik, 1993) apontam que as motivações empresariais para o desenvolvimento de inovação social são oriundas de pressões públicas e objetivam naturalmente a minimização de prejuízos sociais de suas próprias intervenções ou a melhoria da imagem de suas marcas no mercado. Nesse contexto, a inovação social serve para a manutenção da racionalidade capitalista, dada a possibilidade de agregar valor e competitividade ao produto, tornando-o socialmente "correto".

O exemplo clássico e já bem conhecido deste fenômeno referese à responsabilidade social; ela surge como política estatal compensatória sobre as corporações, apoiada em austeridade fiscal e obrigatoriedade de intervenção social. Contudo, a maior parte das ações se constitui numa reinvenção de práticas filantrópicas e assistencialistas primordialmente comprometidas com o lucro e focadas no bem-estar empresarial.

Em 1919, a questão da responsabilidade e discricionariedade dos dirigentes de empresas abertas veio à tona publicamente pelo julgamento na Justiça Americana do caso Dodge versus Ford. Tratava-se da amplitude da autoridade de Henry Ford, presidente e acionista majoritário, em tomar decisões que contrariavam interesses de um grupo de acionistas da Ford, John e Horace Dodge. Em 1916, Henry Ford, argumentando a realização de objetivos sociais, decidiu não distribuir parte dos dividendos esperados, revertendo-os para investimentos na capacidade de produção, aumento de salários e como fundo de reserva para a redução esperada de receitas devido ao corte nos preços dos carros. A Suprema Corte de Michigan se posicionou a favor dos Dodges, justificando que a corporação existe para o benefício de seus acionistas e que diretores corporativos têm livre arbítrio apenas quanto aos meios de se alcançar tal fim, não podendo usar os lucros para outros fins. A filantropia corporativa e o investimento na imagem da corporação para atrair consumidores poderiam ser realizados, na medida em que favorecessem os lucros dos acionistas. (Ashley \& Coutinho, 2000: 3).

Neste caso, tanto a argumentação de Ford para não pagar seus acionistas, quanto as consequências da sentença favorável a Dodges, recaíram sobre justificativas sociais para efetuar investimentos lucrativos. Evidencia-se, histórica e culturalmente, uma implícita tendência de apropriação de conceitos e de mobilizações sociais que passam a ser operados por lógicas instrumentais consolidadas historicamente pela Razão Indolente.

Nesse estudo de caso, Ashley \& Coutinho (2000) evidenciam que, com a criação de determinado imaginário social impulsionado pelos dis- 
cursos globalmente propagados, a opinião pública e os governos rendemse frente ao rótulo socialmente correto e sustentável nas embalagens dos produtos, ampliando a lucratividade das empresas e justificando a apropriação de demandas da esfera social por parte do mundo corporativo.

Assim, a polêmica se expressa, por um lado, com a afirmação de Mitnick (1995) de que, mesmo de maneira implícita, os processos de responsabilidade social trazem discussões firmadas na ética e na moral para a agenda empresarial e que isto por si só valeria o empreendimento estratégico neste conceito. Por outro lado,

tem-se observado, todavia, que por trás do discurso cobertura, que deixa transparecer apenas as boas intenções e as motivações socialmente admissíveis para esse novo paradigma organizacional, existem outras razões que levam as organizações a aderirem ao movimento pelo social, razões essas que nem sempre são assumidas publicamente e, em sua maioria, não são questionadas pelo mundo acadêmico. Pode-se, ainda, apontar para contradições existentes entre o que as organizações pregam sobre as ações ditas sociais e as práticas organizacionais. (Mészáros, 2003: 22).

Em conformidade com o ponto de vista de Mészáros, Soares (2004) apresenta a responsabilidade social empresarial sobre três pilares, a saber: ética empresarial, preservação dos recursos naturais e respeito aos trabalhadores. Realizando análise detalhada de cada um destes elementos e de sua relação direta com a esfera do capital, a autora explicita a incongruência entre o discurso e as práticas empresariais, estas últimas intimamente ligadas à lógica do lucro concluindo que:

Neste contexto, a responsabilidade social corporativa pode ser entendida como uma dupla resposta à atual crise vivenciada pelo capital. A primeira delas, nos termos da dominação da empresa na sociedade atual, que [...] busca se tornar a instituição das instituições. A outra, no sentido que a mudança nos padrões da concorrência, decorrente da crise econômica, obriga as organizações a adaptarem seu processo de trabalho às novas exigências do mercado globalizado e a adequarem sua estrutura aos padrões de parceiros internacionais ou aos requisitos decorrentes de processos de fusão e incorporação. (Soares, 2004: 14).

Considerando as reflexões de Soares (2004) e Mészáros (2002, 2003), a análise crítica e histórica dos elementos fundantes e constitutivos das corporações evidencia limitações na capacidade destas em implementarem práticas sociais efetivas e emancipatórias, visto que a pobreza e a exclusão têm sido, simultaneamente, as consequências e molas propulsoras do modelo de desenvolvimento globalizado baseado na racionalidade mercantil. 


\section{Qualquer inovação não serve}

Há de se respeitar a lógica da dinâmica social que, por pressão, reivindica das corporações alguma ação capaz de remediar as mazelas sociais, erigidas sob a égide da Razão Indolente. Valorosas também são as iniciativas sociais corporativas que, mesmo apresentando incongruências, representam avanço nas agendas de debate. Contudo, adjetivar tais iniciativas de forma quase indiscriminada como inovação social, sem levar em consideração certos princípios éticos e níveis de participação dos envolvidos, pode significar a reprodução de um processo de apropriação do social que historicamente caracteriza o sistema capitalista.

Neste sentido, considerando o debate acumulado no âmbito da Sociologia Econômica e da Sociologia em geral, sugere-se que a ideia de "inovação para compensação" defina, de forma mais apropriada, a maioria das práticas sociais corporativas. Propomos que a inovação social implique num processo efetivamente voltado à emancipação social e à construção de uma sociedade com níveis superiores de participação e oportunidades para todos. Isso é inovar no âmbito social, visto que práticas de cunho mais voluntaristas, filantrópicas e residuais caracterizam uma paradigma mais tradicional na intervenção. Se a inovação na área tecnológica tem critérios rígidos para ser assim conceituada, a área social também os possui e construiu a partir de uma trajetória de práticas assistenciais, protetivas e promotoras. Portanto, a ideia de "inovação para compensação" permite o reconhecimento de que algumas estratégias voltam-se ao combate de mazelas geradas pelo sistema e, em boa parte, engendradas pelas próprias corporações.

A assunção do caráter compensatório de muitas das ações denominadas como inovadoras do ponto de vista social permite a redução da incongruência, a reavaliação das expectativas e a justiça conceitual na medida em que tais práticas, geralmente, não incorporam uma visão crítica acerca da gênese material (desenvolvimento excludente) e imaterial (Racionalidade Indolente) dos problemas sociais. Isso não significa que, em âmbito local ou particular, práticas corporativas não gerem mudanças em trajetórias de vida pessoal ou grupal no sentido de melhoria das condições de vida e bem-estar. Propomos, contudo, que para uma análise e uma transformação societária ou estrutural caracterizar-se enquanto inovação no âmbito social, princípios fundamentais do legado produzido pelas lutas históricas dos movimentos na sociedade devem ser mantidos, tais como a radicalização da democracia, a ênfase nos processos (e não primordialmente nos resultados) e a primazia dos atores sociais.

\section{Para ser inovação social}

Considerando os conceitos, teorias e movimentos constitutivos do campo social apontados (Fleury, 2003; Nanci, 1993; Nascimento, 2007; 
Alencar, 2008; Simoni, 2010 \& Sen, 2000), propomos os seguintes supostos para a inovação social:

a) A radicalização da democracia significa a abertura de espaços de gestão em que a participação popular apresenta alto potencial de ressignificação da esfera pública e do imaginário de sociedade civil.

De um conjunto de experiências de deliberação que se estão processando na América Latina emerge a proposta de democratização radical do Estado e da necessidade de publicizá-lo mediante a criação de instrumentos que permitam ir além do controle social, viabilizando a construção de uma esfera pública de cogestão dos recursos públicos. Nossa curta experiência democrática nos mostra um desequilíbrio entre estado/sociedade, executivo/legislativo onde uma forte tradição tecnocrática e autoritária impede o diálogo franco entre estado e sociedade. (Fleury, 2003: 4).

A inovação social deve sugerir, portanto, uma migração da democracia representativa para a democracia deliberativa, na qual o acesso às informações, a formação crítica e o protagonismo comunitário sejam subsídios para a intervenção no campo social. É eminente a necessidade de construção de uma esfera pública deliberativa em vista do necessário combate às arraigadas tradições assistencialistas, o que só pode ocorrer através do empoderamento dos atores sociais locais. No seio dessa democracia radicalizada encontra-se o respeito ao próximo, apoiado sobre o princípio de justiça social.

O modelo deliberativo é uma concepção substantiva e não meramente procedimental da democracia, envolvendo valores como o igualitarismo e a justiça social. O processo decisório não é para eleger entre alternativas, mas para gerar novas alternativas, o que possibilitaria maior inovação social. Finalmente, é esperado que as decisões assim tomadas propiciassem maior justiça redistributiva e sejam mais sustentáveis. (Fleury, 2003: 5).

Os conceitos de democracia participativa, codeterminação, comunidade de interesse e autogestão contribuem para a diferenciação entre graus maiores ou menores de participação em relação à prática de autogovernar-se. (Nanci, 1993).

Democracia participativa é o tipo menos avançado de organização autogovernada. Seu objetivo principal é forçar os problemas da comunidade a serem considerados em nível estatal ou nacional. Neste sistema, os membros da comunidade elegem representantes que, como delegados, realizam a defesa de seus interesses em espaços de articulação. A grande dificuldade deste modo de organização é o possível distanciamento entre as demandas do delegado e aquelas da comunidade.

Codeterminação é o segundo modo do continum autogoverno. Neste 
caso, o elemento de coesão do grupo é a figura centralizada do líder. Importante destacar que, na codeterminação, o poder formal da organização é exercido pela assembleia, a qual prescreve as regras de funcionamento interno da organização e as ações a serem tomadas pelo líder e demais membros.

O terceiro tipo de autogoverno é a comunidade de interesses, na qual todos lideram. Pelo alto índice de interesses comuns, qualquer pessoa pode falar em nome do grupo. Este tipo de comunidade busca influenciar a sociedade trabalhando, geralmente, com a dinâmica de dividir sua unidade em subunidades básicas. Geralmente os membros derivam do mesmo ambiente ou comunidade, aliados por um denominador comum muito forte e concreto.

Quando a organização chega neste ponto, passa a existir um grande diferencial: a tomada de decisão não se faz mais pelo voto direto, pelo qual a maioria simples decide, mas pelo consenso. Isto garante voz a todos e atribui à minoria o poder de veto.

Por fim, de acordo com Nanci (2003), o último e mais favorável tipo de autogoverno é a autogestão, na qual todos os trabalhadores de um determinado empreendimento ou atores de determinada comunidade tornamse dirigentes dela. Para o autor, dentro do modelo de autogestão encontramos os elementos dos outros modelos. Neste caso, todos podem votar e se transformar em um líder, considerando suas aptidões e as demandas a serem resolvidas.

O quadro a seguir sintetiza cada modelo:

Tabela 2: Modelos participativos. Fonte: Nanci (1993)

\begin{tabular}{|c|c|c|c|c|}
\hline & $\begin{array}{l}\text { Democracia } \\
\text { participativa }\end{array}$ & Codeterminação & $\begin{array}{c}\text { Comunidades de } \\
\text { interesse }\end{array}$ & Autogestão \\
\hline $\begin{array}{l}\text { Principal } \\
\text { atividade }\end{array}$ & $\begin{array}{l}\text { Desenvolvimento } \\
\text { econômico }\end{array}$ & $\begin{array}{l}\text { Desenvolvimento } \\
\text { simbólico }\end{array}$ & $\begin{array}{l}\text { Desenvolvimento } \\
\text { político }\end{array}$ & $\begin{array}{l}\text { Desenvolviment } \\
\text { o sistêmico/ } \\
\text { comunitário }\end{array}$ \\
\hline $\begin{array}{c}\text { Metas de } \\
\text { mudança } \\
\text { s sociais }\end{array}$ & 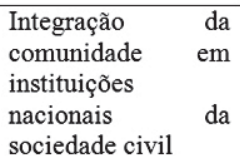 & $\begin{array}{l}\text { Liderança com } \\
\text { base na } \\
\text { comunidade } \\
\text { esta com base na } \\
\text { sociedade geral }\end{array}$ & $\begin{array}{l}\text { Influência } \\
\text { organizatória } \\
\text { baseada em } \\
\text { autogoverno } \\
\text { sobre a sociedade }\end{array}$ & $\begin{array}{l}\text { Autodeterminaç } \\
\text { ão da sociedade } \\
\text { civil }\end{array}$ \\
\hline
\end{tabular}

De acordo com Nanci (1993: 52):

Precisamos ter em mente que as organizações de superfície comuns de autogoverno e de interesse social não são tão simples como parecem. Cada tipo representa uma solução idealizada para a natureza de um conflito particular que a respectiva organização enfrenta e, naturalmente, há diversas variações possíveis de cada tema principal. Depende muito dos interesses sociais envolvidos e da interação 
dos líderes e membros das organizações na medida em que ela se move da democracia participativa para a autogestão.

Desta forma, a dimensão autogestionária supõe a não dissociação no modo de produção entre subjetividade e prática. A dissociação entre trabalho e lazer, função e hobby, vida pessoal e vida profissional é combatida dentro da concepção de autogestão.

A promoção de inovações sociais requer que se considere o processo de gestão e a respectiva capacidade de empoderamento dos atores, sendo desejável a migração da democracia representativa para formas mais participativas que, em última análise, desloquem as ações de poder das atuais estruturas estatais ou privadas para a esfera pública organizada.

O Estado é outro elemento a ser destacado no tocante ao fortalecimento de sua função intermediadora, sem chamar a centralidade para si, mas garantindo espaços democráticos de formação, discussão e deliberação guiadas pelo principio da justiça social. Nessa perspectiva, ele se caracteriza como Estado-facilitador dos processos sociais.

É pertinente, ainda, retomarmos as contribuições de Granovetter (in Swedberg, 2000) sobre a importância das redes; elas não são frutos de harmônicas relações guiadas pela justiça e pelo interesse de bem comum. Desta forma, estar atento às ambiguidades das diversas motivações oriundas dos atores sociais, deixando-as explícitas e respeitando-as, torna-se necessário na análise de relações entre empresas, Estado e sociedade civil, articulados na busca pela inovação social. Esses elementos também podem balizar a gestão e os processos decisórios com liberdade de expressão dos diferentes pontos de vista, acesso às informações e controle comunitário sobre os benefícios e a difusão da inovação, o que indicaria um genuíno processo de inovação social e de radicalização da democracia.

b) Ênfase nos processos significa opor-se à lógica de que, para o fim pretendido, justificam-se quaisquer meios. Conforme visto, qualquer tipo de inovação não serve genuinamente à lógica social. Sendo assim, enfatizar o processo significa privilegiar o compartilhamento entre empresas, Estado e sociedade civil no planejamento, intervenção, apropriação dos resultados, difusão e avaliação do processo de inovação.

Para tanto, é primordial que se realize um inventário “junto com” e “sobre” a comunidade, a respeito das estratégias e práticas adotadas por ela ao longo do tempo no combate às suas principais dificuldades a fim de garantir que qualquer forma de intervenção estatal ou corporativa parta do conhecimento local. Trata-se de fazer justiça histórica com os diversos movimentos e empreendimentos aos quais a comunidade vem se dedicando, o que significa um passo firme em direção à boa apropriação da inovação por parte da comunidade que, desta forma, consegue contextualizá-la no seu cenário sócio-histórico. 
A análise de alguns estudos sobre políticas públicas (Alencar, 2008 \& Simoni, 2010) demonstra que a maior parte das intervenções acumula baixos índices de efetividade devido ao abismo existente entre a formalidade objetivada nos discursos das políticas e os contextos sociais. Os autores trazem inúmeros exemplos de intervenções que desrespeitam peculiaridades locais e trabalham com uma linha homogeneizadora e planificadora das realidades e dos fenômenos sociais, o que gera descompasso entre a teoria e a prática e, consequentemente, ineficiência nos resultados.

A ênfase no processo e no conhecimento comunitário pré-existente como elementos centrais ao processo de inovação social em contexto corporativo vincula-se ao debate sobre o tipo de desenvolvimento desejado. O economista indiano Amartya Sen (2000), Nobel de Economia, apresenta impactante estudo sobre a concepção moderna ocidental de desenvolvimento e economia. Partindo da constatação histórica de que crescimento econômico nem sempre - e na maior parte das vezes - não é proporcionalmente equivalente a desenvolvimento social, e apoiado nas clássicas concepções aristotélicas de economia, o autor desconstrói a definição de economia unicamente como mercantil.

Com efeito, a origem da economia foi significativamente motivada pela necessidade de estudar a avaliação das oportunidades que as pessoas têm para levar uma vida boa e as influências causais sobre estas oportunidades. Além do emprego clássico desta ideia por Aristóteles, noções semelhantes foram muito usadas nos primeiros textos sobre contas nacionais e prosperidade econômica, cujo pioneiro foi Willian Petty no século XII, seguido por Gregory King, François Quesnay, Antonie Laurent Lavoisier e outros. (Sen, 2000: 41).

Sendo assim, o conceito de desenvolvimento que se apresenta ao longo da sua obra versa sobre a liberdade de acesso dos indivíduos aos elementos constitutivos básicos, alinhando-se à sua capacidade em atingir o tipo de vida que eles valorizam. Neste contexto, a garantia dos direitos básicos é central e não necessita de nenhuma justificativa econômica para existir. Acessibilidade aos direitos é finalidade que se justifica por si mesma.

O êxito de uma sociedade deve estar avaliado, nesta visão, primordialmente segundo as liberdades substantivas que os membros dessa sociedade desfrutam. Esta posição avaliatória difere do enfoque informacional de abordagens normativas mais tradicionais, que se concentram em outras variáveis, como utilidade, liberdade processual ou renda real. (Sen, 2000: 24).

As análises de Sen promovem certa inquietação sobre os processos de desenvolvimento com primazia do econômico, os quais se desenvolvem e pulverizam-se ao longo da história ocidental e originam processos de pobreza e desigualdade social. Em determinado momento, chega-se ao questionamento sobre as formas e os índices de avaliação do 
desenvolvimento, comprovando-se que as atuais ferramentas avaliativas são parciais, tendenciosas e insuficientes para uma visão mais crítica e socialmente justa.

Como consequência, desencadeia-se a necessidade de construção de novos instrumentos de avaliação, como o Índice de Felicidade Interna Bruta (FIB), desenvolvido com apoio de Sen e adotado por diversos países em todo o globo. O FIB, resumidamente, apresenta o conceito de felicidade como central a esta nova concepção de desenvolvimento e esquadrinha os elementos econômicos como um dos nove itens que compõem os critérios avaliativos desta escala. Desta forma, o conceito de desenvolvimento retorna ao que, filosoficamente, motivou o nascimento da economia como ciência: garantir a capacidade das pessoas em acessar elementos que tornem suas vidas minimamente próximas do que desejam para si mesmas. (Sen, 2000). Portanto, fundamental ao processo de inovação social é garantir, no discurso e na prática, clareza quanto ao tipo de desenvolvimento desejado, sendo necessário um equilíbrio entre os aspectos econômicos, liberdades e capacidades.

c) Por fim, ao tratarmos de uma genuína inovação social, a primazia dos atores sociais no processo mostra-se imprescindível. Mulgan (2007 apud Bignetti, 2011) afirma que inovações sociais são:

Novas ideias que funcionam na satisfação de objetivos sociais; atividades inovativas e serviços que são motivados pelo objetivo de satisfazer necessidades sociais e que são predominantemente desenvolvidas e difundidas através de organizações cujos propósitos primários são sociais. (p. 32).

Tal concepção mostra-se central na medida em que as ações de inovação social devem ser difundidas primordialmente por entidades que tenham fins socialmente arraigados em sua constituição. Este elemento garante que associações e cooperativas comunitárias, assim como movimentos sociais e organizações sem fins lucrativos, tenham suas histórias respeitadas, sua centralidade garantida e assim aumentem as possibilidades de efetividade das intervenções.

Um emblemático e real caso a este respeito é o de a uma cadeia multinacional de supermercados que passou a distribuir sacolas ecologicamente corretas aos consumidores mediante a compra de qualquer produto no somatório de cinquenta reais. Contudo, estas bolsas eram confeccionadas e distribuídas por uma grande e formal indústria têxtil, mostrando desconhecimento e desvinculação da cadeia de supermercados com um grande número de associações e cooperativas de costureiras articuladas historicamente ao movimento social e que se encontravam no mesmo bairro, nos arredores do centro de compras. O exemplo demonstra a diferença entre inovação social e compensação, permeada pelo marketing social.

O investimento das empresas em produtos ecologicamente corretos 
e sustentáveis é legítimo, mas para ser socialmente justo, deve ser realizado em parceria com atores locais para a distribuição justa dos benefícios materiais e imateriais da ação. É neste sentido que se retoma a necessidade da organização comunitária, bem como a importância da figura do Estado como facilitador da relação entre corporações e sociedade civil; Estado este que, em seu processo de democratização, tenha crescentemente como base as próprias comunidades e os movimentos sociais. Assim, estruturar um processo genuíno de inovação social significa garantir que cada um dos atores envolvidos realize a parte que lhes cabe como copartícipes da inovação, de acordo com a sua vocação, disposição e estrutura organizacional.

\section{Finalizando}

A desigualdade evidente em âmbito global não é um processo natural, mas socialmente produzido a partir de uma racionalidade que privilegiou a acumulação de capital e secundarizou a reprodução da vida. A Sociologia Econômica tem buscado compreender teoricamente esse processo de cisão através de estudos sobre a imbricação do econômico no social, os quais identificaram sentidos mais amplos e complexos para as ações econômicas. Tais sentidos não se restringem à explicação de motivações psicológicas e de significados do comportamento dos indivíduos nas atividades econômicas, mas também visam apreender a importância da estrutura social na economia.

Porém, tal intento é insuficiente na medida em que a incorporação da estrutura social na análise se dá sob a tendência da racionalidade mercantil, especialmente se considerarmos que o princípio do mercado tem tratado o social de forma subalterna aos interesses do capital. Sem se levar em conta essa racionalidade prevalente, a própria inovação social -ainda que sob princípios de criação de valor social e compartilhamento de ações e resultados- será funcional à reprodução ampliada das desigualdades.

Apesar de novas e modernas roupagens, sem a transformação de determinada racionalidade a inovação social não se diferenciará -em termos ético-políticos e nos efeitos materiais e imateriais produzidos- de formas assistencialistas, paternalistas ou filantrópicas de intervenção social. Há que se lembrar de que tais formas vinculam-se a perspectivas teóricometodológicas positivistas-funcionalistas, as quais predominaram no campo das ciências sociais e na sociedade há décadas, não podendo, portanto, serem conceitualmente consideradas inovadoras.

O estudo demonstrou que, de modo geral, as práticas definidas como inovação social pelas corporações mostram-se limitadas para a instauração de mudanças fundamentais na realidade social e na Racionalidade Indolente. A nosso ver, para serem inovadoras, tais mudanças não poderiam restringir-se a melhorias nas estruturas sociais e nos ganhos econômicas, mas incidir na eliminação de formas de produção de desigualdades, assim como 
no alavancar de processos e estruturas de organização, participação e deliberação comunitária. Isso requer a superação de lógicas e práticas que criam o ignorante, o residual, o inferior, o local e o improdutivo, incorporando as múltiplas dimensões de um processo emancipatório e sustentável de mudança social.

Além dos procedimentos, desenhos e técnicas, a inovação social necessita inovar a si mesma através da abertura a novas racionalidades que deem sentido ampliado a noções fundamentais como participação, processo e protagonismo dos sujeitos envolvidos. A metarreflexão e o questionamento acerca da economia como sinônimo de mercado, do desenvolvimento como expansionismo produtivista ilimitado e do progresso como avanço tecnológico e científico - bem como a vinculação desses elementos à gênese das desigualdades - podem permitir a pluralização de modos de viver e de produzir e gerar ações efetivamente inovadoras, criadas de forma participativa e que incorporem a riqueza e os interesses presentes na sociedade.

Ainda que movido por diferentes motivações, o desejo corporativo de promover a inovação social é importante e deve ser estimulado na medida em que a responsabilidade no enfrentamento da questão social compete a todos os segmentos sociais. Cabe, contudo, destacar que uma genuína novidade no campo das intervenções sociais requer uma crítica à concepção de desenvolvimento predominante, bem como o reconhecimento da lógica da justiça conceitual e da primazia do social e seus atores, sob pena de se compensar mazelas criadas pelo próprio sistema e assim retroalimentar os enfoques mercadológicos como princípio de existência, embasados na crença e no discurso de que se está inovando. 


\section{Nota}

${ }^{1}$ Vide estudos de caso: Pontes, Elizabeth Reis. A responsabilidade social das empresas e a estratégia organizacional: análise de uma empresa na Amazônia. Belém, 2011; Monteiro, Maurílio de Abreu. Meio século de mineração industrial na Amazônia e suas implicações para o desenvolvimento regional. Revista Estudos Avançados - MG, 2005; Francisco R. C. Fernandes, Adão B. da Luz, Gerson M. M. Matos. Centro de Tecnologia Mineral - Tendências Tecnológicas Brasil 2015: Geociências e Tecnologia Mineral/Eds. Rio de Janeiro: CETEM/ MCT, 2007; Kneipp, Jordana M., Gomes, Clandia M. Gestão para a sustentabilidade em empresas do setor mineral. Revista de Ciências da Administração, Universidade Federal de Santa Catarina, Florianópolis, Santa Catarina, 2012v14n33p52. 


\section{Bibliografia}

Alencar, E. F. (2008, agosto), Gênero, políticas públicas e sustentabilidade social na várzea do Alto Solimões/AM. Anais do Simpósio Intersecções entre Gênero e Sociodiversidade na Amazônia. SC, 1, Florianópolis.

Ashley, P. A., \& Coutinho, R. B. G. (2000, setembro), Responsabilidade social corporativa e cidadania empresarial: uma análise conceitual comparativa. Anais do ENANPAD, SC, 4, Florianópolis.

Bignetti, L. P. (2011), “As inovações sociais: uma incursão por ideias, tendências e focos de pesquisa”. Ciências Sociais Unisinos, 47(1), 3-14.

Castel, R. (1997), “As transformações sociais”. In: Belfiore, Wanderley (orgs) Desigualdades e a questão social. EDUC, São Paulo.

Ferrarini, A. V. (2008), Pobreza: possibilidades de Construção de Politicas Emancipatórias. Oikos, São Leopoldo.

Fleury, S. (2003), Democracia com exclusão e desigualdade: a difícil equação. Relatório A Democracia na América Latina do Programa das Nações Unidas para o Desenvolvimento. Brasília.

Guattari, F., \& Rolnik, S. (1993), Micropolítica: cartografias do desejo. Vozes, Petrópolis.

Idem (2003), As três ecologias. Papirus, Campinas.

Mészáros, I. (2002), Para além do capital: rumo a uma teoria da transição. Boitempo, São Paulo.

Mészáros, I. (2003), O século XXI: socialismo ou barbárie?, Boitempo, São Paulo.

Mitnick, B. M. (1995), "Systematics and CSR: the theory and processes of normative referencing”. Business and Society, 34(2), 5-33.

Mulgan, G., \& Tucker, S. (2007), Social innovation what it is why it matters and how it can be accelerated. Recuperado de http://www.sbs.ox.ac.uk/ centres/skoll/research/Documents/Social\%20Innovation.pdf

Nanci, V. C. (1993), Autogestão: o nascimento das ONGs. Brasiliense, São Paulo.

Nascimento, C. (2007), Autogestão e Economia Solidária. Recuperado de http://www.tau.org.ar/upload/89f0c2b656ca02ff45ef61a4f2e5bf24/ nascimento_autogest.pdf

Raud-Mattedi, C. H. J. (2005), “Análise crítica da Sociologia Econômica 
de Mark Granovetter: os limites de uma leitura do mercado em termos de redes e imbricação”. Revista Política e Sociedade, 4(6), 59-82.

Reis, E. P. (1989), “Reflexões sobre o homo sociologicus”. Revista Brasileira de Ciências Sociais, n. 11(4), 23-33.

Santos, B. S. (2002), Produzir para viver: os caminhos da produção não capitalista (Coleção reinventar a emancipação social para novos manifestos). Civilização Brasileira, Rio de Janeiro.

Idem (2000), A crítica da razão indolente: contra o desperdício da experiência (Coleção para um novo senso comum: a ciência, o direito e a política na transição paradigmática). Cortez, São Paulo.

Idem (2004), $3^{\mathrm{a}}$ edição. - Democracia e Participação: O Caso do Orçamento Participativo de Porto Alegre. Cortez, São Paulo.

Sen, A. (2010), Desenvolvimento como liberdade. Companhia das Letras, São Paulo.

Simoni, J. (2010), A revitalização do extrativismo: práticas de economia solidária e sustentabilidade. Recuperado em http://desafios.ipea.gov.br/ sites / $000 / 2$ / boletim_mercado_d e_trabal ho/m t 42 / 07_Eco_01_revitalizacao.pdf

Soares, G. M. P. (2004), Responsabilidade social corporativa: por uma boa causa!? RAE-eletrônica, 3(2), 2-15. Recuperado em http://rae.fgv.br/ sites/rae.fgv.br/files/artigos/10.1590_S1676-56482004000200012.pdf

Swedberg, R. (2004), “Sociologia econômica: hoje e amanhã”. Tempo Social, 16(2), 7-34.

Banco Palmas. Em www.bancopalmas.org.br, acessado em 04 de dezembro de 2012.

Recibido: 05.11.2012

Aceptado: 15.02.2013 